\title{
A review of underlying surface parameterization methods in hydrologic models
}

\author{
ZHAO Lingling ${ }^{1,2}$, ${ }^{*}$ LIU Changming ${ }^{2}$, SOBKOWIAK Leszek ${ }^{3}$, WU Xiaoxiao ${ }^{4}$, \\ LIU Jiafu ${ }^{5}$
}

1. Guangzhou Institute of Geography, Guangzhou 510070, China;

2. Institute of Geographic Sciences and Natural Resources Research, CAS, Beijing 100101, China;

3. Adam Mickiewicz University, Institute of Physical Geography and Environmental Planning, 61-680 Poznań, Poland;

4. Department of Earth and Environment, Anhui University of Science \& Technology, Huainan 232001, Anhui, China;

5. Maoming Branch Hydrological Bureau of Guangdong Province, Maoming 525000, Guangdong, China

\begin{abstract}
Numerous topography, land-cover, land-use, and soil-type parameterization methods are required to simulate the hydrologic cycle. In this paper, using the principles of hydrologic cycle simulation, 20 methods commonly applied to runoff-yield simulation are analyzed. Additionally, parameterization methods used in 17 runoff-yield simulation methods and 15 confluence methods are discussed, including the degree of parameterization. Next, the parameterization methods are classified into four categories: not clearly expressed; calibrated; deterministic; and physical-conceptual. Furthermore, we clarify responses and contributions of different parameterization methods to hydrologic cycle simulation results. Finally, major weaknesses of simplified descriptions of complex rational and physical mechanisms in the parameterization methods of the underlying surfaces in hydrologic models are outlined, and two directions of future development are estimated, looking toward simple practicality and complex mechanization.
\end{abstract}

Keywords: hydrologic cycle simulation; watershed topography; land use and cover; watershed characteristics; parameterization

\section{Introduction}

The natural water circulation system is large, multi-linked, and dynamic. Studies on water circulation began with observations and experiments on precipitation, evaporation, interception, infiltration, runoff, and other singular processes (Liu et al., 2014). Only since the mid-1950s has the hydrologic cycle been considered a complete system. Thus, hydrologic models have been proposed, resulting in more comprehensive studies on watershed processes and interactions.

Received: 2018-05-05 Accepted: 2018-10-10

Foundation: National Natural Science Foundation of China, No.41771044, No.41501046; Water Conservancy Science and Technology Innovation Project of Guangdong Provincial Water Resources Department, No.2014-14, No.2016-14; Natural Science Foundation of Guangdong Province, No.2015A030310234; GDAS' Project of Science and Technology Development, No.2019GDASYL-0104003, No.2018GDASCX-0101, No.2017 GDASCX-0806; Science and Technology Project of Guangdong Province, No.2018B030324002

Author: Zhao Lingling (1980-), PhD and Associate Professor, specialized in hydrological cycle simulation and water resources management. E-mail: linglingzhao@gdas.ac.cn

*Corresponding author: Liu Changming, Professor and CAS Academician, E-mail: liucm@igsnrr.ac.cn 
Watershed hydrologic simulation is based on the application of physics, mathematics, and hydrology via the generalization of the watershed system according to its input conditions (e.g., precipitation, evapotranspiration, watershed underlying surface). It requires simulation of watershed hydrologic processes, including the outflow processes at the outlets (Rui, 1997; Zhao et al., 2013). Over the last century climate change and the human activities have resulted in dramatic global environmental changes, including the water circulation system, which has far-reaching impacts on the socio-economic development. Thus, water-cycle simulation is a basis for water resource evaluation, allocation, management, and decision-making in terms of flood control and mitigation, soil erosion, water resource development and utilization, environmental protection of water resources, water ecosystem restoration, road and urban planning, watershed response to human activities, etc. (Singh, 1988; Entekhabi et al., 1999; Lu et al., 2006; Lu et al., 2010; Li et al., 2015; Liang et al., 2015; Xia et al., 2017).

Watershed topography, land use, and land cover are closely related to water interception, infiltration, evaporation, and other factors. They directly influence outflow production and runoff at the watershed outlet. Thus, the underlying surface is particularly important to simulation (Singh, 1995). There are numerous underlying surface parameterization approaches to hydrologic cycle simulation. For example, in the soil and water assessment tool (SWAT) model, the Soil Conservation Service (SCS)-curve method is often applied to calculate runoff. Canopy interception, surface water storage, and infiltration prior to runoff production are incorporated into the initial loss. The Storm-Water Management Model (SWMM), Hydrological Informatic Modeling System (HIMS), and water and energy transfer processes (WEP) models use the Green-Ampt method and the Horton method to calculate infiltration, plant interception, depression storage, and other factors that cause precipitation loss. Similarly, parameterization methods of flow concentration differ. Whereas the Xin'anjiang, Stanford IV, HSPE, and HIMS models use the unit-hydrograph method to calculate overland flow, the TOPMODEL and distributed time-variant gain hydrological model (DTVGM) often calculate overland flow by using the method of linear reservoir. River discharge is calculated using the theory of kinematic waves, dynamic waves, diffusion waves, and the Muskingum method, which are based on the Saint-Venant equations. Different methods of flow concentration have different degrees and methods of expression regarding the underlying surface. This paper analyzes the parameterization methods of the underlying surface in hydrologic cycle simulation and investigates problems existing in parameterization of topography, land use, land cover, and soil types. It also outlines future trends.

\section{Runoff yield simulation methods in hydrologic cycle modeling}

Major runoff-yield simulation methods include storage-full runoff, runoff yield under excess infiltration, mixed runoff, and rainfall-runoff coefficient of correlation methods (Bao, 2006; Bao et al., 2008). See Table 1.

Runoff-yield simulations in the hydrologic modeling include calculation of overland-flow and river-flood routing. Methods and equations of river-flow simulation are the Saint-Venant, kinematic wave, dynamic wave, diffusion wave, inertial wave, an algorithm for reservoir flood control, Muskingum method, the Muskingum-Cunge method, variable storage coefficient method, etc. (Zhang et al., 2007). 
In many studies on surface runoff in large- and medium-sized watersheds, the overland-flow stage is often ignored, and only the river flow is considered. However, in a small watershed, that stage cannot be ignored. Thus, overland-flow simulation methods include isochrones method, unit hydrograph method, linear reservoir equation, non-linear reservoir equation, and kinematic wave equation ( $\mathrm{Li}, 2007)$.

Table 1 Classification of runoff-yield methods in hydrological models

\begin{tabular}{|c|c|c|}
\hline Runoff-yield method & Calculation method & Hydrological model \\
\hline $\begin{array}{l}\text { Rainfall-runoff coeffi- } \\
\text { cient of correlation }\end{array}$ & $\begin{array}{l}\text { SCS, Nonlinear runoff } \\
\text { methods }\end{array}$ & $\begin{array}{l}\text { DTVGM (Xia et al., 2002; Xia et al., 2005a; Xia et al., } \\
\text { 2005b), HIMS (Liu et al., 2006; Liu et al., 2008), SWMM } \\
\text { (Huber et al., 2008), SWAT (Neitsch et al., 2011; Arnold et } \\
\text { al., 1998), HEC-HMS (Feldman,1981) }\end{array}$ \\
\hline \multirow[t]{2}{*}{ Storage-full runoff } & $\begin{array}{l}\text { Soil water storage capacity } \\
\text { curve }\end{array}$ & $\begin{array}{l}\text { Xin'anjiang (Zhao,1984), VIC (Liang et al., 1994; Liang et } \\
\text { al., 1996), EasyDHM (Lei et al., 2010a, 2010b) }\end{array}$ \\
\hline & Topographic index & $\begin{array}{l}\text { TOPMODEL (Beven et al., 1984; Beven et al., 1995), } \\
\text { TOPKAPI (Liu et al., 2002) }\end{array}$ \\
\hline \multirow[t]{2}{*}{$\begin{array}{l}\text { Runoff yield under } \\
\text { excess infiltration }\end{array}$} & $\begin{array}{l}\text { Soil infiltration capacity } \\
\text { curve }\end{array}$ & $\begin{array}{l}\text { Shanbei model (Zhao, 1984), water tank model (Xu, 2009), } \\
\text { EasyDHM, TOPMODEL, VIC }\end{array}$ \\
\hline & Green-Ampt & SWAT, WEP, HIMS, SWMM, PRMS (Xu, 2009), HEC-HMS \\
\hline Dynamic equation & Richards equation & $\begin{array}{l}\text { VIC, WEP (Jia et al., 2001a, 2001b), VIP (Mo et al., 2004), } \\
\text { MIKE SHE (Abbott et al., 1986a, 1986b) }\end{array}$ \\
\hline
\end{tabular}

Note: SWAT: Soil and Water Assessment Tool; SCS: Soil Conservation Service curve method; SWMM: Storm-Water Management Model; HIMS: Hydrological Informatic Modeling System; WEP: Water and Energy transfer Processes models; HSPF: Hydrological Simulation Program-Fortran; DTVGM: Distributed Time-Variant Gain hydrological Model; HEC-HMS: Hydrologic Engineering Center Hydrologic Model System; VIC: Variable Infiltration Capacity; EasyDHM: Easy Distributed Hydrological Model; TOPMODEL: Topography based Hydrological Model; TOPKAPI: Topographic Kinematic Approximation and Integration; PRMS: Precipitation-Runoff Modeling System; VIP model: Vegetation Interface Processes; MIKE SHE: MIKE Système Hydrologique Européen; SWMIV: Stanford Watershed Model IV; HBV: Hydrologiska Byråns Vattenbalansavdelning Model

Commonly used methods of overland- and river-flow simulations in hydrologic models are shown in Table 2.

Table 2 Classification of confluence methods in hydrological models

\begin{tabular}{lll}
$\begin{array}{c}\text { Confluence } \\
\text { process }\end{array}$ & \multicolumn{1}{c}{ Calculation method } & \multicolumn{2}{c}{ Hydrological model } \\
\hline $\begin{array}{l}\text { Overland } \\
\text { flow }\end{array}$ & Unit hydrograph method & $\begin{array}{l}\text { Xin'anjiang model, SWMIV, HSPF, HEC-1, TOPMODEL, } \\
\text { VIC-3L, HIMS, SWAT } \\
\end{array}$ \\
& Isochrones method & Xin'anjiang model, HIMS \\
& Linear reservoir equation & Xin'anjiang model, TOPMODEL, DTVGM \\
& Non-linear reservoir equation & SWMM, TOPKAPI \\
River & Kinematic wave equation & HEC-1, TOPKAPI, DTVGM, WEP-L (Jia et al., 2006), EasyDHM \\
flow & Dynamic wave equation & SHE, VIC-3L (Yuan et al., 2004), PRWS, WEP-L \\
& Muskingum method & Xin'anjiang model, HBV, HEC-1, SWAT, HIMS, EasyDHM \\
& Variable storage coefficient method & SWAT, EasyDHM \\
\hline
\end{tabular}

Note: SWAT: Soil and Water Assessment Tool; SCS: Soil Conservation Service curve method; SWMM: Storm-Water Management Model; HIMS: Hydrological Informatic Modeling System; WEP: Water and Energy transfer Processes models; HSPF: Hydrological Simulation Program-Fortran; DTVGM: Distributed Time-Variant Gain Hydrological Model; HEC-HMS: Hydrologic Engineering Center Hydrologic Model System; VIC: Variable Infiltration Capacity; EasyDHM: Easy Distributed Hydrological Model; TOPMODEL: Topography based Hydrological Model; TOPKAPI: Topographic Kinematic Approximation and Integration; PRMS: Precipitation-Runoff Modeling System; VIP model: Vegetation Interface Processes; MIKE SHE: MIKE Système Hydrologique Européen; SWMIV: Stanford Watershed Model IV; HBV: Hydrologiska Byråns Vattenbalansavdelning Model 
The purpose of the model application and time scales are related. Usually an hour or even a minute time scale is required for flood forecasting. However, in water-resource management, a daily scale is used, and a monthly scale meets most requirements for climate change and other environmental impact assessments. Because different time scales lead to different requirements regarding the level of detail of the description of the runoff-yield, even within the same model, a different time scale causes different methods to be selected for simulation. Therefore, the data requirement of the model also differs.

\section{Parameterization methods of underlying watershed in rainfall-runoff}

Parameterization methods in rainfall-runoff process simulation are discussed in relation to four aspects: the interception by vegetation and depression storage; the rainfall-runoff correlation method; the storage-full runoff method; and the runoff yield under excess infiltration method.

\subsection{Interception by vegetation and depression storage}

There are numerous hydrological simulation methods that consider interception by vegetation and depression storage.

\subsubsection{Interception by vegetation}

In hydrologic simulation, it is necessary to consider interception, which depends on the type and density of vegetation cover, season, precipitation characteristics, and other factors. In practice, empirical models have usually been applied, such as the Horton model (1935, 1940), LKP model, Meriam model, and others. Horton proposed a series of empirical equations for different plants and used a relatively wide range of empirical formula (see Table 3) with empirical values of parameters $S_{v}$ and $C$.

\subsubsection{Depression storage}

On plains and slope zones, owing to relatively large numbers of hollows, depression storage is relatively large, significantly changing the watershed response. In 1979, Ullah and Dickinson $\left(1979 \mathrm{a}\right.$; 1979b) proposed a relationship between the depression volume, $V\left(\mathrm{~cm}^{3}\right)$, and the surface slope, $s$, (see Table 3). In 1979, Linsley et al. (1975), based on characteristics of the surface depressions, derived a relationship between depression storage volume, $V$, and depression storage capacity $S$ (see Table 3 ). During runoff-process simulation, the impact of different terrain on the depression storage is relatively large.

\subsection{Rainfall-runoff correlation method}

The SCS runoff curve method and the non-linear Time-Variant Runoff Gain method are discussed.

\subsubsection{SCS runoff curve method}

The SCS runoff curve method is a kind of empirical relationship, which is based on measured data and through statistical analyses and summary. To calculate surface runoff, the SCS-curve method, the canopy interception of rainfall, surface water storage, and infiltration are integrated into initial loss. Therefore, it is not necessary to separately calculate canopy interception of rainfall (SCS, 1993). 
The empirical formula of surface runoff and interception by the SCS-curve method can be seen in Table 3. The influence of land use and land cover on the runoff process is mainly reflected by a $C N$ value. The greater the $C N$ value, the smaller watershed interception and the larger surface runoff. SCS model developers have provided a detailed reference table with given $C N$ values. However, owing to large errors in runoff, the determination of $C N$ values is still a bottleneck of the SCS curve application in practice (Mishra et al., 2003).

\subsubsection{Non-linear Time-Variant Runoff Gain method}

Hydrologic non-linear Time-Variant Gain Model (TVGM) was developed by Xia et al. (2002a, 2002b) as a simple and effective method for non-linear hydrologic systems. Main equations related to watershed runoff can be seen in Table 3.The monthly-scale DTVGM model uses $N$ from the Bagrov model for classification of main land use types (Wang, 2005).

\subsection{Storage-full runoff}

The watershed storage curve method and the topographic index method are commonly used in storage-full runoff methods.

\subsubsection{Watershed storage curve method}

Runoff processes in a watershed are spatially not uniform. Before the entire watershed reaches full-storage runoff, partial areas already exist with full storage and runoff. Generally, the watershed water storage capacity curve characterizes uneven spatial distribution of soil water deficits. The watershed water storage curve equation is given in Table 3. During hydrologic simulation, the input parameters often use the watershed-average storage capacity, $W M$, and the water storage capacity distribution exponential curve, $b$. The value of $W M$ is related to the watershed drought condition, and the constant, $b$, reflects the unevenness of the watershed water storage capacity (Zhao et al., 1963). The watershed water storage curve method does not express the influence of terrain, land use, land cover, or soil on runoff. However, the $b$ parameter implicitly shows the effects of the underlying surface.

\subsubsection{Topographic index}

Beven et al. (1984) proposed TOPMODEL, in which the topographic index, $\ln (\alpha / \tan \beta)$, is used to reflect hydrologic phenomena in a watershed, determine the size of the original area through water content, and determine water content via the topography index. The relationship between topographic index and water content is derived in accordance with the steady-state theory, assuming that the dynamic of groundwater levels changes in a watershed.

\subsection{Runoff yield under excess infiltration method}

There are two infiltration methods: the infiltration curve method and the infiltration formula.

\subsubsection{Infiltration curve method}

\section{1) Infiltration capacity curve}

Infiltration laws in a watershed are represented by an infiltration curve. The main principles and formulas of the soil infiltration capacity curve are shown in Table 3 . When calculating the runoff infiltration curve, to improve the accuracy and reduce the effects of spatial and temporal non-uniform distribution of rainfall intensity on runoff, rainfall duration should 


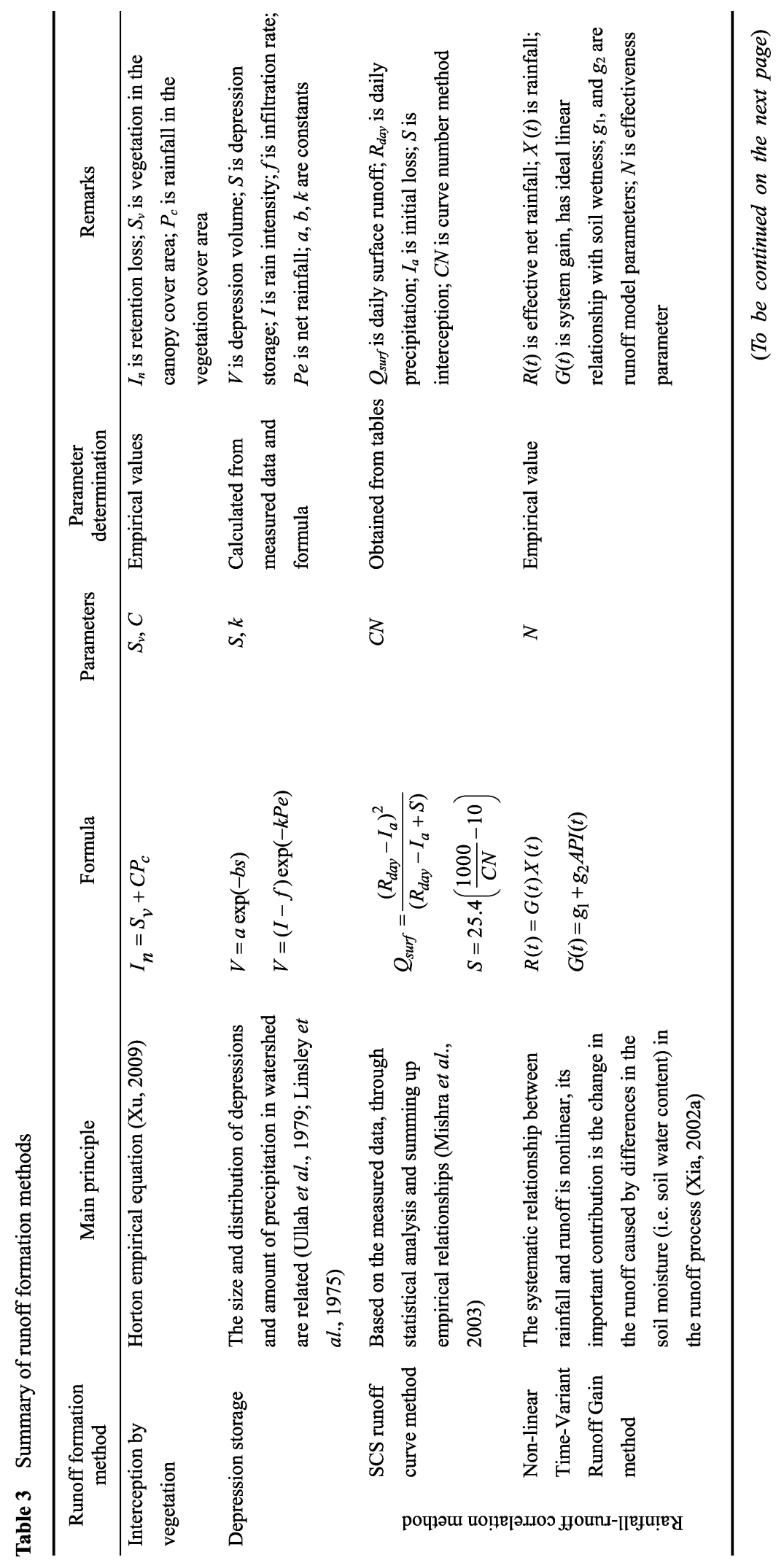




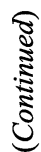

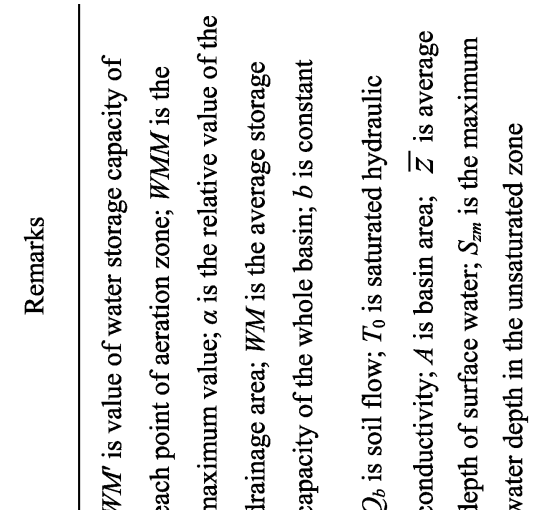

窟

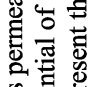

资

急密

$\stackrel{2}{2} \stackrel{3}{2}$

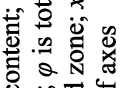

氙记

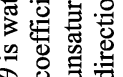

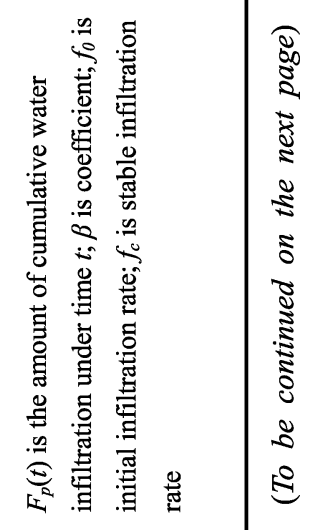

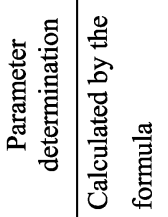

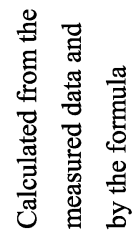

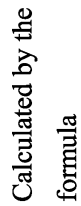

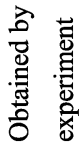

总

IN की

$\checkmark$

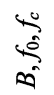

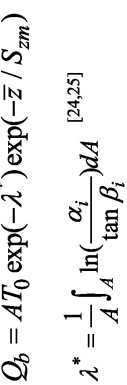

ำ

$\stackrel{ \pm}{ \pm}$

s

षे

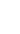

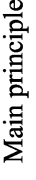

$\overbrace{\substack{11 \\ 0}}^{\frac{1}{1}}$

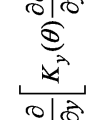
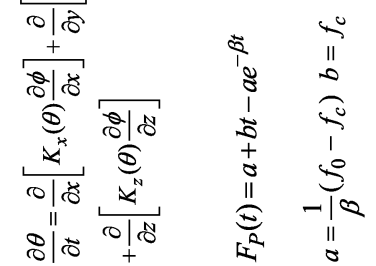

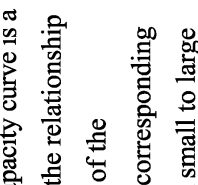

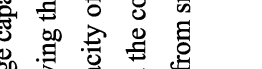

兽

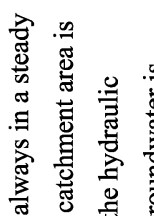

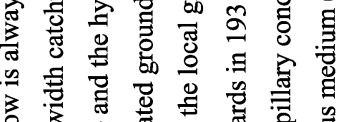

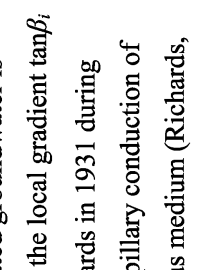

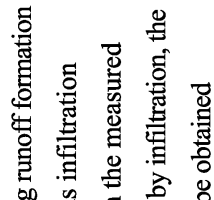

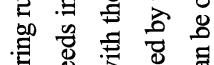




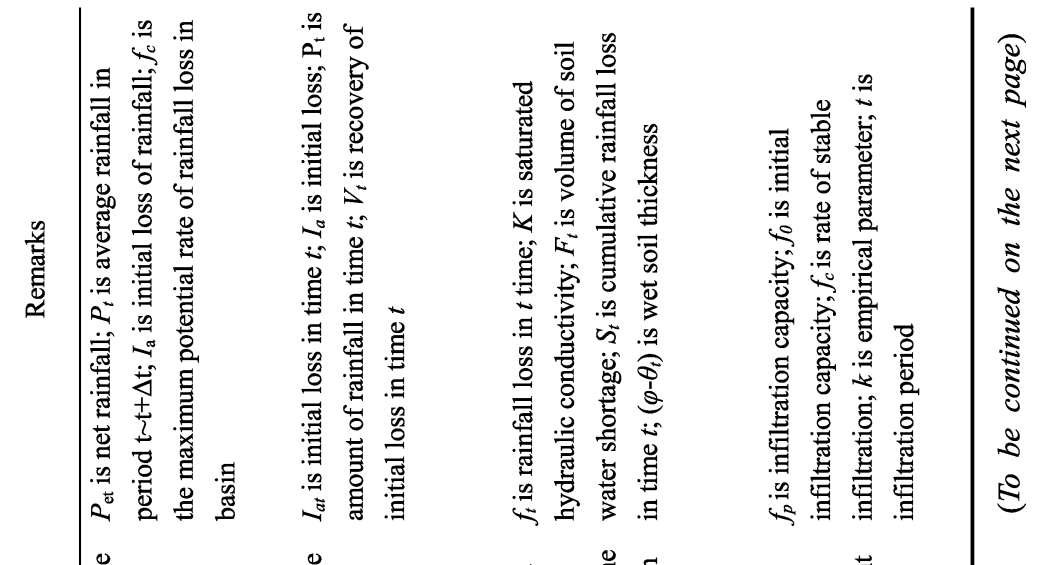

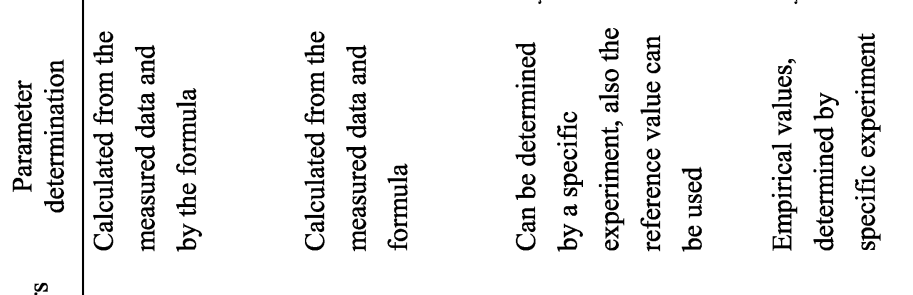

焉

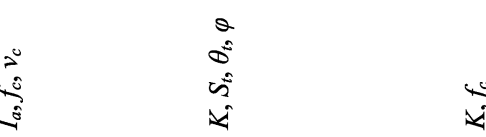

$\stackrel{\leftrightarrow}{\dot{x}}$

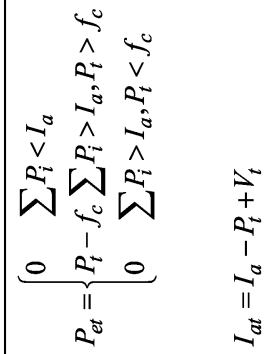

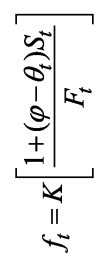

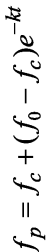

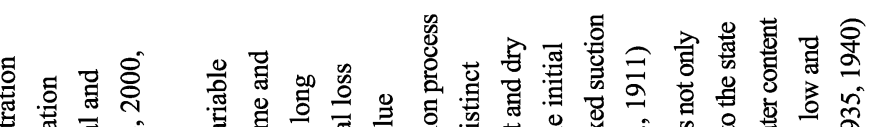

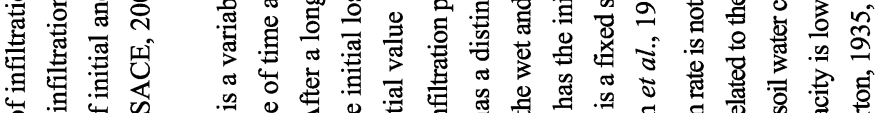

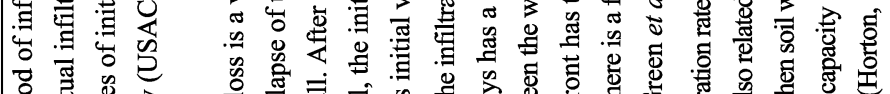

吉

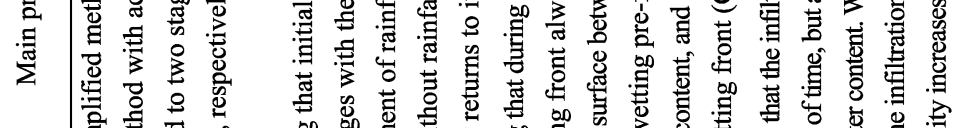

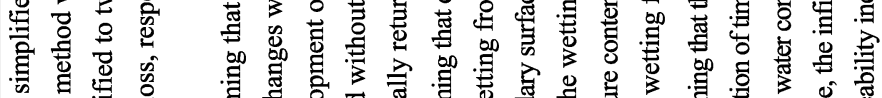

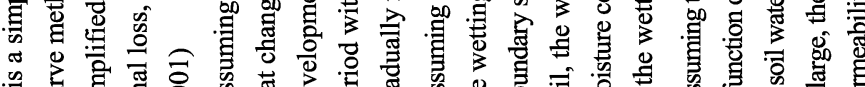

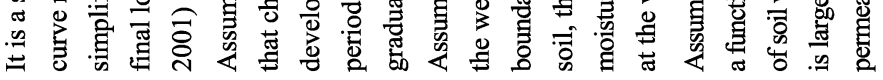

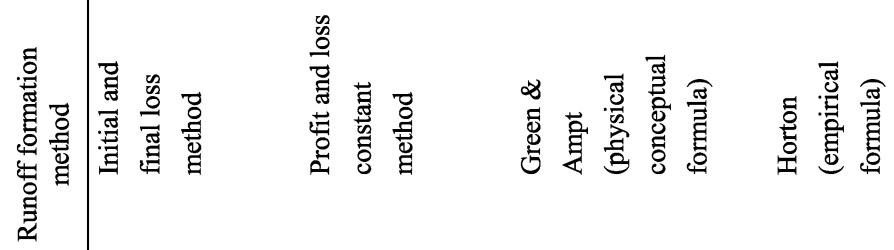




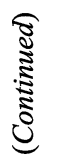

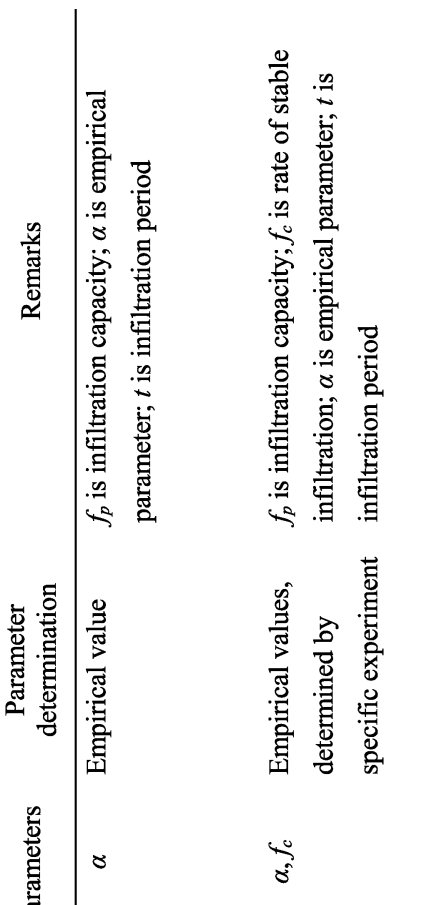

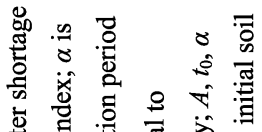

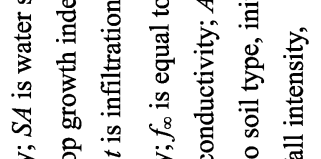

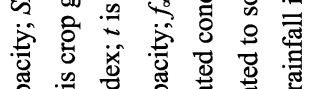

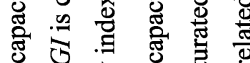

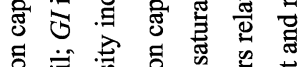

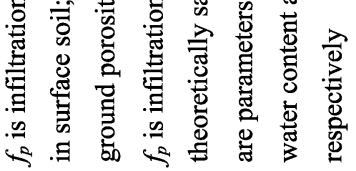

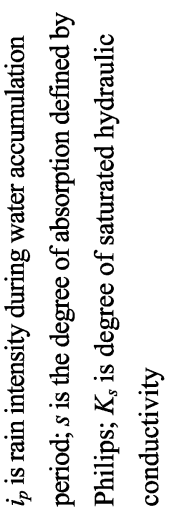

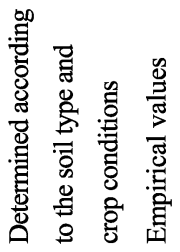

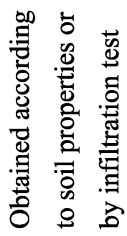

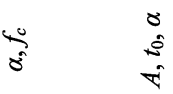

2

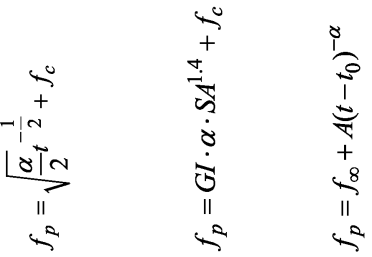

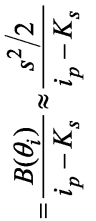

:

4

4

4

웅

政

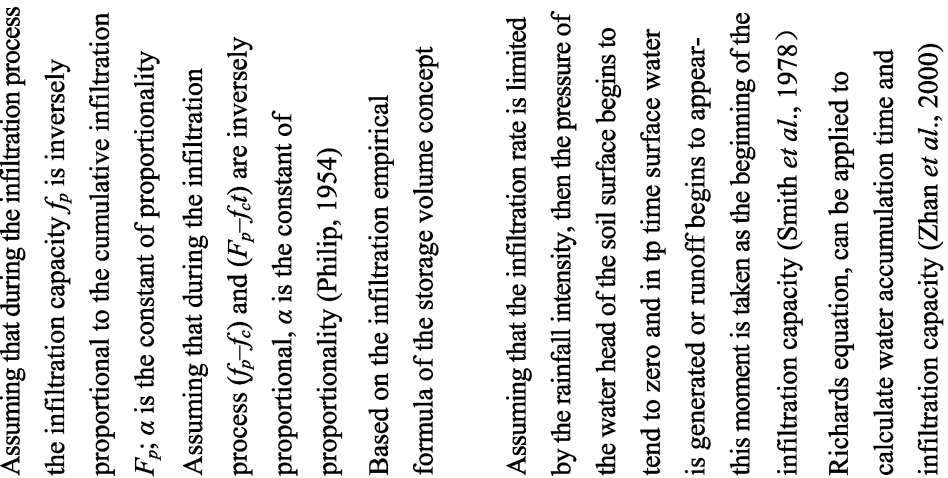

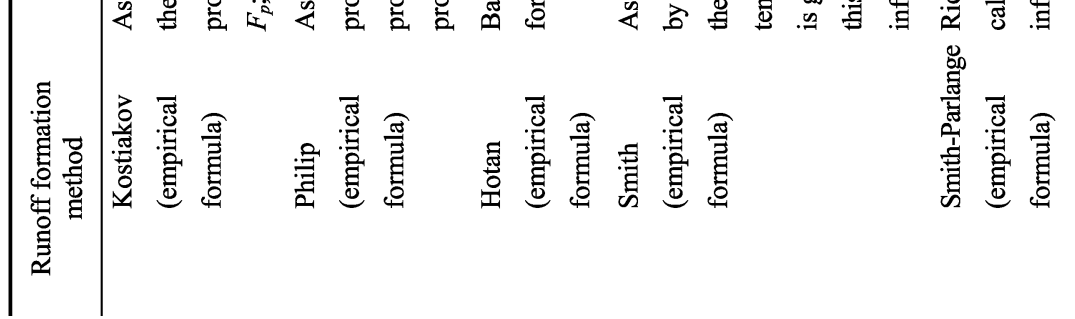


not be large (e.g., minutes), and the watershed area should be divided into smaller units per the distribution of rainfall stations. However, to determine the infiltration capacity curve, runoff data and field experiments are required to obtain, which in practice is difficult to achieve.

2) Simplified infiltration capacity curve

The initial and final loss method is a simplified infiltration curve, where the actual infiltration process is simplified and split into two stages: initial and final. The initial loss before runoff produced is represented by the watershed average depth of water. The final loss is represented by average infiltration rate, $f c$. Skaggs and Khaleel (1982) gave reference values of $f c$ for different soil types. Under conditions of data scarcity, the initial rate of infiltration can be set to reference values.

The profit and loss constant method is similar to the initial and final loss method. The profit and loss method assumes that the initial loss is a kind of variable changing with the development of time and rainfall. After long-term lack of rainfall, the initial loss will gradually return to the initial value. Thus, in addition to the two parameters (i.e., initial loss $I_{a}$ and subsequent infiltration rate $f_{c}$ ), the recovery rate $v_{c}$ is required.

\subsubsection{Infiltration formula}

Infiltration formulas can be divided into two types: physical conceptual and the experimental. Among the commonly used physical conceptual infiltration formula, the Green-Ampt formula is popular. Experimental infiltration formulas are more diversified and include the Horton, Kostiakov, Philip, Hotan, Smith, and Smith-Parlange formulas. The main formulas and their parameters are shown in Table 3. From the table can be seen, empirical infiltration formulas for runoff are often calculated to determine the experimental parameters.

Vegetation interception during the runoff formation of hydrologic cycle simulation considers land use and land cover effects on the water cycle. For depression storage, it considers the influence of topography. Rainfall-runoff yield correlation methods experimentally derive or use semi-quantitative rainfall-runoff relationships to characterize the influence of the underlying surfaces. During runoff yield under excess infiltration methods, the soil in the underlying surface is described by empirical parameters of the infiltration formula, whereas topography, land use, and land cover are implicit influencing factors expressed indirectly.

In summary, hydrological cycle simulation considers the impact of land use and land cover on the water cycle during vegetation interception and the runoff yield process. It also considers the effect of terrain on the water cycle during the filling process and the influence of terrain on the water cycle during the storage process. The rainfall-runoff correlation characterizes the influence of the underlying surface via an empirical relationship or semi-quantitative relationship obtained by experiment. The influence of terrain and land use is described primarily using empirical parameters. The runoff yield under excess infiltration of soil in the underlying surface is usually described using empirical parameters of the infiltration formula with the infiltration curve method, whereas terrain and land use cover are implicitly influencing factors and are not directly expressed.

In the future, runoff mechanisms will be controlled by the water-balance principle in the watershed. Thus, it is necessary to further strengthen the quantitative study on the runoff mechanism for several reasons. First, hydrological processes are always modeled on different scales, including the spatial scale (i.e., slope, basin, region) and the time scale (i.e., minute, hour, month, year, multi-year). Second, the underlying surface of the watershed has 
strong individuality, and there are many factors influencing the underlying surface during runoff, including land use, land cover, topography, soil characteristics, and the initial water content of the watershed. These main factors are considered in the current hydrologic cycle model. However, the complexity of physical mechanisms and the diversity of underlying surfaces make it difficult to describe accurately. Finally, intense human activities significantly exert impact on the underlying surface, making it more diversified and complex. Simultaneously, many constructions and hydraulic structures destroy the natural flow.

\section{Parameterization methods of underlying watershed surfaces in the con- fluence process simulation}

This section presents the simulation of overland-flow confluence and stream-flow routing. These two processes are usually simulated separately during hydrological cycle modeling.

\subsection{Simulation of overland-flow confluence process}

Empirical surface-flow confluence process modeling is based on the linear superposition theory, and most methods include the isochronous streamline method, the unit hydrograph method (e.g., time unit, instantaneous unit, geomorphic unit), the linear reservoir method, and other simplified methods (Zhan et al., 2000).

\subsubsection{Isochrone method}

The isochrone method simplifies the physical process of overland flow and gives relatively satisfactory results in distributed hydrologic models. The main principles and formulas of the method are shown in Table 4. The confluence speed of overland flow is the key factor in the isochrone method, usually based on measured data and experiments. Therefore, effects of underlying watershed surfaces are not clearly expressed and are implied in the empirical parameters of the isochrones.

\subsubsection{Unit hydrograph method}

The unit hydrograph method is an empirical simulation method in which a watershed is considered without considering the unevenness of the net rainfall and the underlying surfaces. This corresponds to the ratio and superposition conditions. The main formulas of the unit hydrograph, the instantaneous unit, and the geomorphologic unit are given in Table 4.

Based on a series of linear reservoirs, J. E. Nash et al. $(1957,1960)$ used spatial characteristics, improved the unit-line method, and proposed the instantaneous hydrograph concept. However, in the Nash instantaneous unit hydrograph, certain empirical parameter determinations remain, and the unit hydrograph cannot be solely based on underlying watershed surface information.

In 1979, Rodriguez-Iturbel proposed the concept of Geomorphic Instantaneous Unit Hydrograph (GIUH), which linked probability theory, the method of underlying surface information, and the unit-line method. V. K. Gupta (1980) extended this theory and proposed a geomorphic instantaneous unit hydrograph formula expressed by topographic and hydraulic parameters. Using the GIUH is an effective way of determining flow confluence in areas having no information.

The Nash instantaneous unit hydrograph method and the GIUH are based on characterization of the physical mechanism of the influence of watershed topography on runoff. How- 
ever, it is based on the hypothesis of an entire river watershed. Thus, it cannot provide a spatial description and simulation of the flow confluence process and is unable to handle the case of a large watershed with uneven precipitation distribution.

\subsection{Stream-flow routing}

Stream-flow routing is based on the equation of flow continuity and the equation of energy conservation with the Saint-Venant equation as the theoretical basis. This equation system is based on the physical stream-flow confluence mechanism and considers river slope and roughness. This equation system belongs to the first-order hyperbolic quasilinear partial differential equations, which can be solved by the numerical solution. However, the solution is complicated and does not necessarily provide satisfactory results.

\subsubsection{Simplified momentum equation}

The dynamic equations of the Saint-Venant system can be simplified by neglecting certain items. Thus, different types of flood waves (e.g., kinematic, dynamic, diffusion, inertial etc.) can be obtained. Presently, commonly used kinematic waves, dynamic waves, and diffusion waves, neglecting the inertial term in the dynamic equation and adding the flood wave term described in the equation is the dynamic wave. The inertial piece in the momentum formula in the diffusion wave is neglected. Each momentum fluctuation equation is a dynamic wave in the momentum formula (Govindaraju et al., 1990; Singh, 1994).

Compared to other methods of calculation, a relatively lower flow confluence geomorphologic information input is required to use the kinematic wave method, which is relatively simple. Therefore, it is commonly applied to overland-flow yield and distributed hydrologic model calculations (Orlandini et al., 1999). Saint-Venant equation and the simplified momentum equation inputs mainly require measured river-section data.

\subsubsection{Other empirical equations}

The simplified momentum equation simplifies the continuity equation of the Saint-Venant equation system into the following river-section water-balance equation:

$$
\frac{I_{1}+I_{2}}{\Delta t}-\frac{Q_{1}+Q_{2}}{\Delta t}=V_{2}-V_{1}
$$

where $I_{1}$ and $I_{2}$ are the initial and final inflow discharges, respectively; $Q_{1}$ and $Q_{2}$ are the initial and final outflow discharges, respectively; $V_{1}$ and $V_{2}$ are the initial and final river channel storage capacities, respectively; $\Delta t$ is the time interval.

Dynamic equation can be simplified to the water amount tank storage equation in the river section, which is substituted by an approximate relation among $I, Q$, and $V$. The outflow process is calculated on the basis of inflow, and different approximations give different methods of calculation. Among the most commonly used are the reservoir-flood routing method (Zhang et al., 2002; Rui, 2004), the Muskingum method (Mccarthy, 1938), the Muskingum-Cunge method (Cunge, 1969; Bajracharya et al., 1997), and the variable storage coefficient method. Their main formulas are given in Table 4.

In the Muskingum method, parameters $K$ and $X$ must be determined first. $K$ is the average propagation time in the river section. Its value depends on the river-section length and wave speed. Parameter $X$ represents the relative impact of inflow and outflow on the storage capacity, and its range is $[0,1] . K$ and $X$ are determined experimentally. 


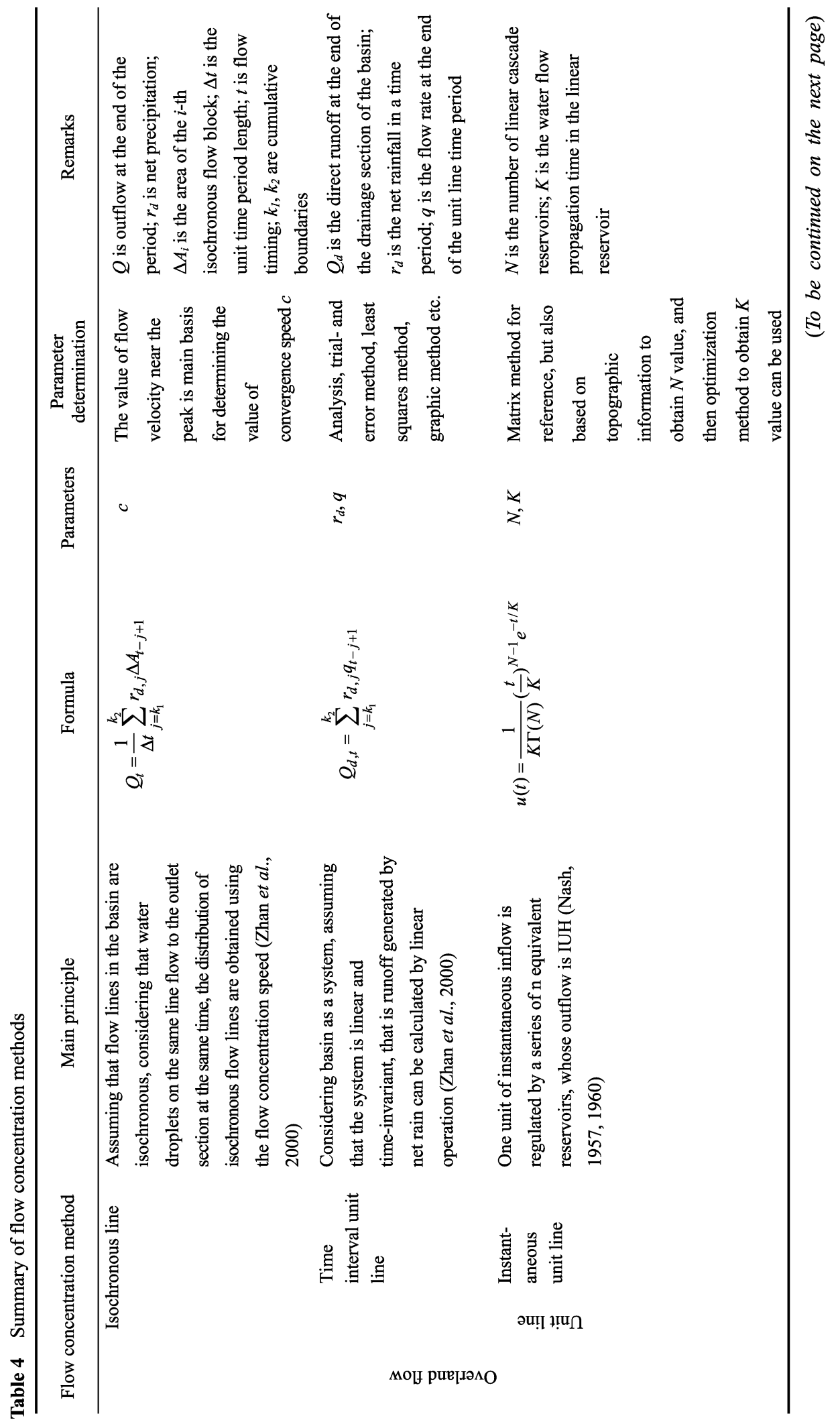




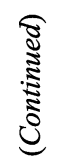

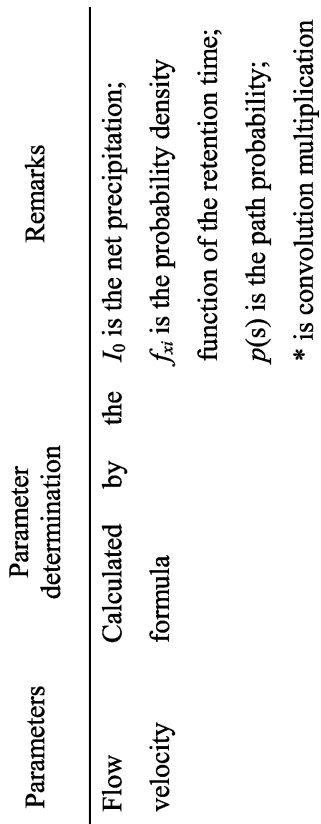

今.

焉

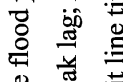

总吉

节要

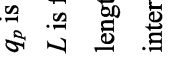

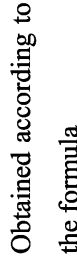

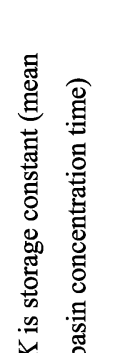

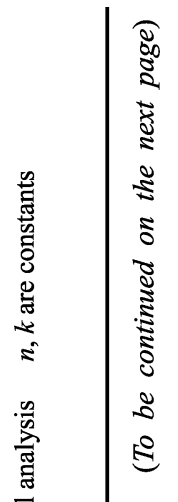

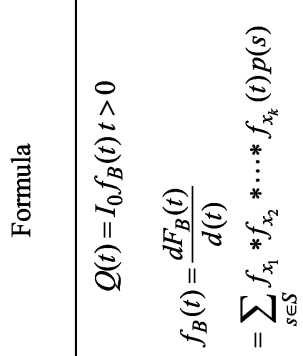

0
$\hat{a}$
$\hat{a}$

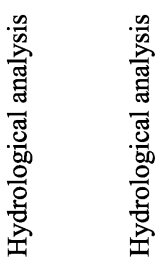

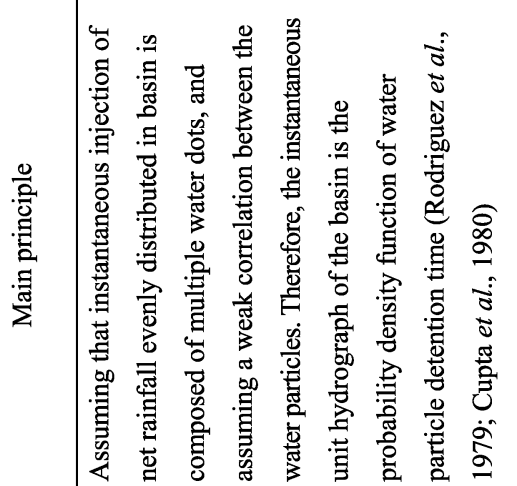

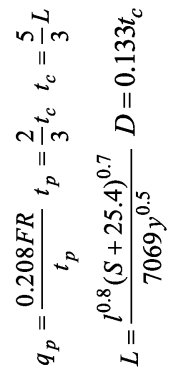

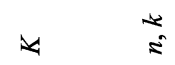

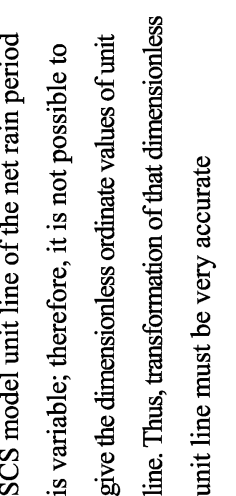

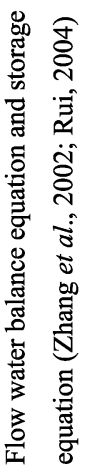

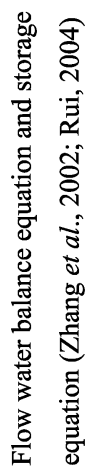

홀

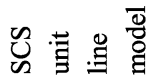

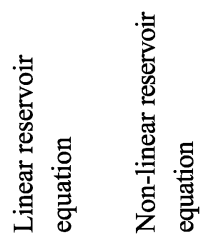


نَّ

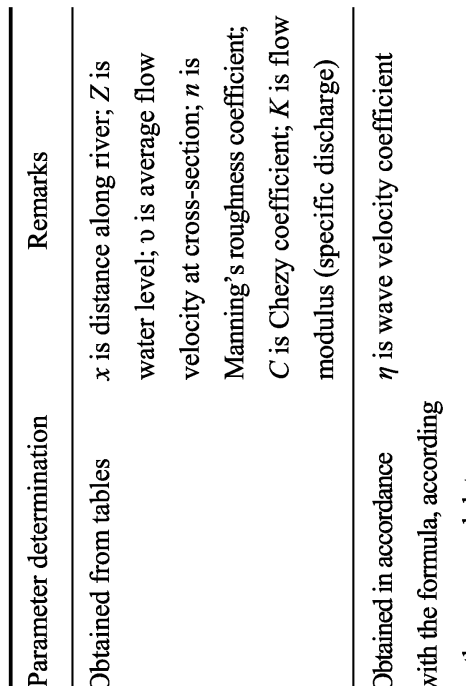

离

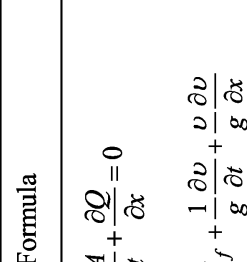

穴|๘

N/

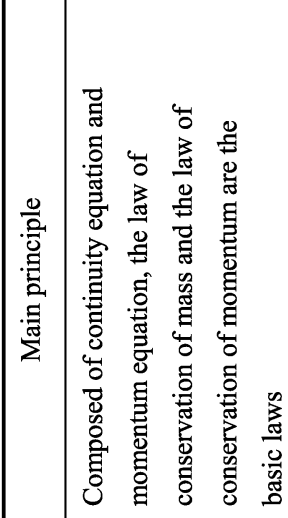

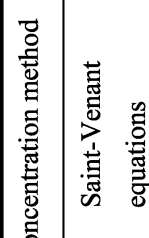
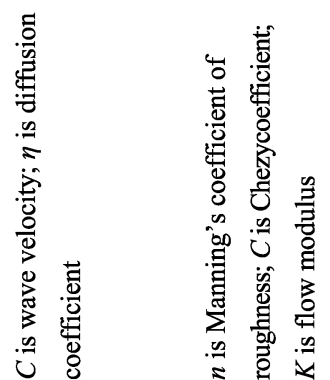

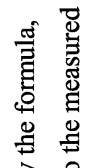

家

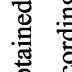

苛

i

4
$\vdots$
5

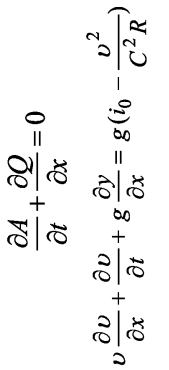

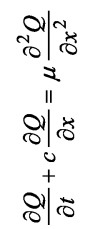

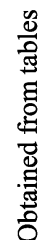

우 


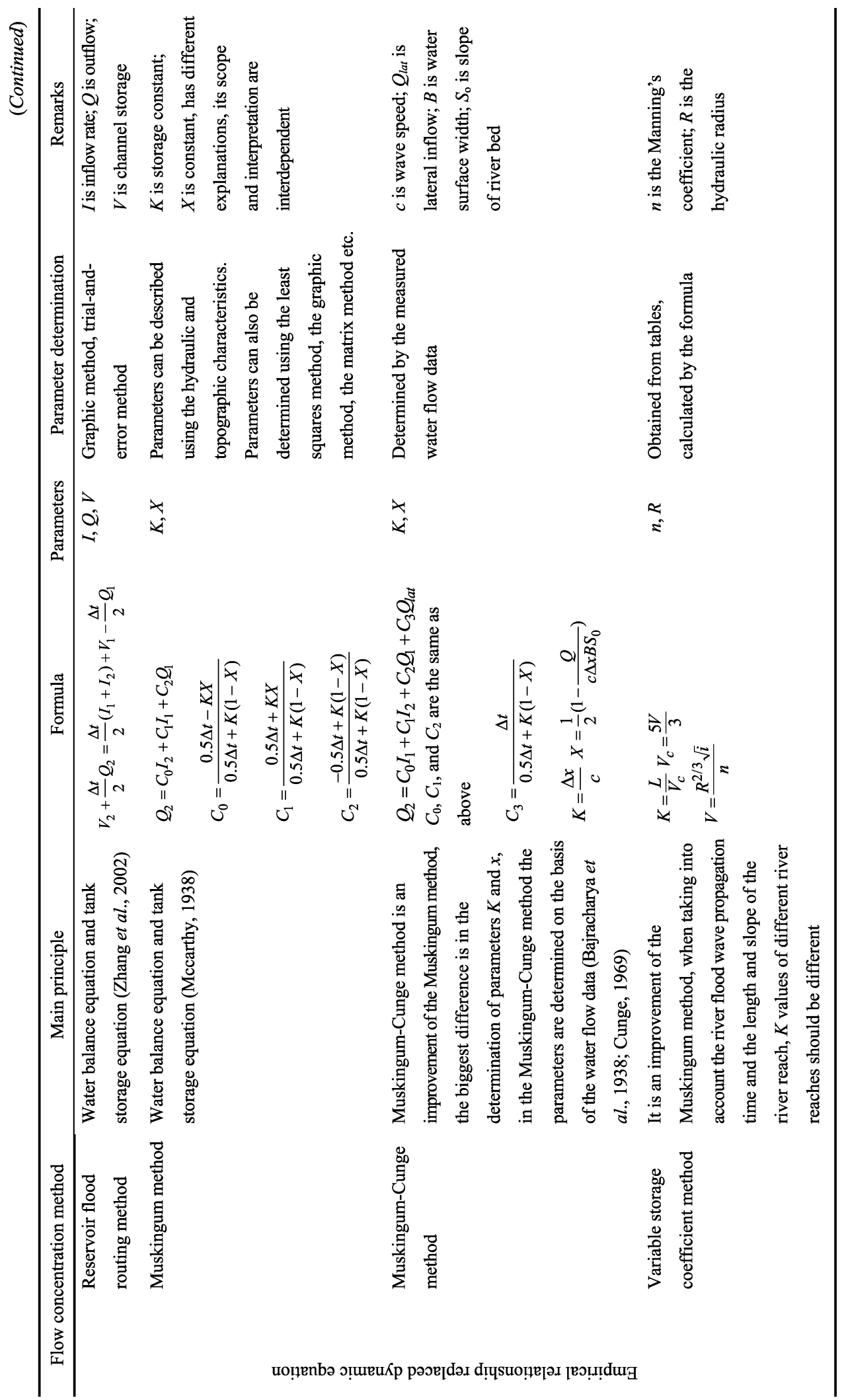


The Muskingum-Cunge method's biggest difference from the Muskingum method is how it determines parameters $K$ and $X$. In the Muskingum-Cunge method, these parameters are calculated from the time-step length, the river-bed slope, and the flood-wave velocity. The calculation formulas are given in Table 4. To some extent, the Muskingum-Cunge method reflects the influence of watershed topography and spatial characteristics of the river network on the flow-yield process.

Topography has a relatively large impact on flow concentration, and it is also a factor that is most studied. In small watersheds, land cover and other factors affect the runoff processes via hydraulic roughness and other properties. Current studies focus on areas with measured data or those where empirical relationships can be established.

Overland flow simulation is based on the confluence process, based on the water-balance principle and hydrodynamic theory. For example, the isochrone method assumes that there is a line that reaches the outlet of a basin at the same time, obtaining its distribution based on the confluence speed. The unit line and SCS unit line are based on the measured data of the basin to reverse the flow process. The instantaneous unit line is based on the function of the connection reservoirs to simulate the confluence process. Furthermore, the instantaneous unit line of the geomorphology is based on the flow. The probability density of residence time is simulated in the confluence process. Topography greatly influences the confluence process, and it is the most influential factor. For small watersheds, the surface cover surface characteristics affect the runoff process via hydraulic characteristics, such as roughness. Current research focuses on using measured data to establish empirical relations.

Confluence methods are based on flow and energy equations to simulate the course of the river flow. The equations are simplified, depending on assumptions and precision requirements. These methods ensure a clear response to the mechanism of the underlying river channel surface. However, for practical applications, they have shortcomings, including the randomness of the underlying surface, including the assumption of the existence of premises and the actual inconsistency. In the hydrologic cycle simulation, river discharge calculations require generalization and simplification of slope and river channel, partially or completely ignoring the spatial variability of hydraulic characteristics. It uses uniform parameters to correct model operations, which significantly limits the descriptive abilities and the spatial precision of the confluence methods.

\section{Classification of the parameterization methods}

Watershed rainfall-runoff simulation parameterization methods can be divided into four categories, depending on the degree of topographical parameterization. The first includes methods not clearly indicated by the effects of terrain and land use on rainfall-runoff processes. The second uses empirical parameters to express the influence of terrain, land use, and land cover in runoff yield and outflow concentration, which are calibrated with parameter data. The third is the deterministic parameters category, which is based on the empirical relationship between terrain, land use, land cover and runoff yield and concentration process, the expressed parameters can be obtained by looking up tables or simple calculation. The fourth is the physical conceptual category, in which the relationships among topography, land cover, land use, and rainfall-runoff parameterization are established by physical mechanisms. 
Owing to the parameterization of the watershed topography, land use, land cover, and soil type in the rainfall-runoff simulation of underlying surface methods, the degree of the parametric description the physical mechanism can be classified as shown in Tables 5 and 6 .

Table 5 Classification of parameterization in runoff-yield processes

\begin{tabular}{lll}
\hline & Category & \multicolumn{1}{c}{ Runoff-yield method } \\
\hline $\begin{array}{l}\text { Rainfall-runoff coefficient } \\
\text { of correlation }\end{array}$ & Deterministic parameters & SCS runoff curve method \\
Storage-full runoff & Calibrated parameters & Non-linear Time-Variant Runoff Gain method \\
& Deterministic parameters & Soil water capacity demand curve method \\
Runoff yield under & Not clearly expressed & Topographic index \\
excess infiltration & Physical conceptual & Richards equation \\
& Calibrated parameters & Infiltration curve method \\
& Initial and final loss method \\
& Green \& Ampt (physical concept formula) \\
& Profit and loss constant method \\
& Horton (empirical formula) \\
& Kostiakov (empirical formula) \\
& Philip (empirical formula) \\
& Hotan (empirical formula) \\
& Smith (empirical formula) \\
& Smith-Parlange (empirical formula) \\
& & \\
& &
\end{tabular}

Table 6 The classification of flow concentration parameterization methods

\begin{tabular}{|c|c|c|c|}
\hline \multicolumn{3}{|c|}{ Flow concentration method } & Category \\
\hline \multirow{7}{*}{$\begin{array}{l}\text { Overland } \\
\text { flow con- } \\
\text { centration }\end{array}$} & \multicolumn{2}{|l|}{ Isochronous line } & Calibrated parameters \\
\hline & \multirow[t]{4}{*}{ Unit hydrograph } & Time interval unit line & Not clearly expressed \\
\hline & & Instantaneous unit line (J.E. Nash) & Calibrated parameters \\
\hline & & GIUH & Physical conceptual \\
\hline & & SCS runoff curve & Deterministic parameters \\
\hline & \multicolumn{2}{|l|}{ Linear reservoir equation } & Calibrated parameters \\
\hline & \multicolumn{2}{|c|}{ Non-linear reservoir equation } & \\
\hline \multirow{8}{*}{$\begin{array}{l}\text { River flow } \\
\text { routing }\end{array}$} & \multicolumn{2}{|l|}{ Saint-Venant equations } & Calibrated parameters \\
\hline & \multirow{3}{*}{$\begin{array}{l}\text { Simplified dynamic } \\
\text { equation }\end{array}$} & Kinematic wave equation & Deterministic parameters \\
\hline & & Diffusion wave equation & \\
\hline & & Dynamic wave equation & \\
\hline & \multirow{4}{*}{$\begin{array}{l}\text { Other empirical equa- } \\
\text { tions replacing dy- } \\
\text { namic equations }\end{array}$} & Reservoir flood routing method & Calibrated parameters \\
\hline & & Muskingum method & \\
\hline & & Muskingum-Cunge method & \\
\hline & & Variable storage coefficient method & \\
\hline
\end{tabular}

\section{Extant problems of parameterization methods and future trends}

Because of the diversity and spatial variability of the underlying surface, the scale effect of the hydrological process (Wood et al., 1988) and the intense human activities (Kuk-Hyun et 
al., 2014; Tang et al., 2015; Liu et al., 2016; Zhang et al., 2016), we observe complexity of the underlying surface in the hydrological cycle. Thus, in a typical watershed hydrologic cycle model, toward the underlying watershed surface topography, land use, land cover, and soil type in the rainfall-runoff process, the degree of description of the physical mechanism empirical parameters prevail. Most of the empirical parameters are obtained via calibrated parameters. The class of deterministic parameters is usually established on parameter tables or empirical relationships. In the physical-conceptual category, there are certain physical equations to express their response. However, with the development of technology, the problem of solving complex equations becomes simpler. Additionally, the more complex equations complicate the hypotheses and parameters, making them often difficult to satisfy, owing to the lack of observational data.

Models are simulations of objective reality or abstract processes. Thus, the hydrologic model is an abstraction of the complex natural hydrologic cycle in a watershed. On the one hand, the application of the hydrologic cycle model aims to explore the laws of nature, approximating the process using various experiments and mathematical equations. Over time, it more accurately describes the natural water cycle. With advances in physics and mathematics, this type of model becomes more complex and provides more accurate characterizations of natural mechanisms. Categories of physical concepts and deterministic parameters represent the second trend. Parameterization methods include physical mechanisms. However, these methods are relatively limited. On the other hand, future research will have more space for exploration. Models have been built to solve real problems, but simplified simulations have little effect on the accuracy of a modeled process. Even so, the simplest calculation that uses minimum data leads to a better and more thorough understanding of phenomena. Such models are simpler and more practical. The above-mentioned methods, including those not clearly expressed, calibrated parameters, and deterministic parameters, represent the first trend, in which the parametric approach provides a simplified empirical relationship to represent the underlying surface in the watershed hydrologic cycle.

As for the relationship between the two aforementioned trends, the processes described as the first trend are more detailed. Thus, the equations will become more complex, and the uncertainty of the model will increase. However, exploration of its mechanism can provide a development paradigm for the second trend and more accurately solve the problem of its application.

\section{Discussion}

Hydrologic cycle simulation is widely used in studies of environmental changes. Watershed topography, land use, land cover, soil type, and other underlying surfaces are closely connected to precipitation, infiltration, and evaporation. They have direct impacts on the rainfall-runoff processes, whereas the flow yield directly affects the flow at the watershed outlet. Thus, topography, land use, and land cover are particularly important in hydrologic simulation.

There are numerous parameterization methods for the underlying surfaces regarding hydrologic models. In this paper, the following simulated aspects of the underlying surfaces in the hydrologic cycle simulation are reviewed.

(1) Rainfall-runoff process simulation methods commonly used in hydrologic cycle simulation are classified. Then, the parameterization of the terrain, land use, land cover, and 
soil types are explored. The role of that mechanism is portrayed.

(2) The parameterization methods of the underlying surface in the physical mechanism of the rainfall-runoff process are divided into four categories: the not-clearly expressed; calibrated parameters; deterministic parameters; and physical-conceptual. Currently, the most commonly used parameterization methods are calibrated parameters category, which describe the physical mechanism of topography, land use and land cover and soil types in runoff yield and concentration in watershed underlying surface. These are followed by the deterministic parameters category, generally determined by a parameter table or empirical relationship. In the case of physical conceptual category parameterization methods, physical equations represent the response relationships, however, their application faces difficulties, owing to the lack of data supporting the boundary conditions.

(3) Returning to the natural model, with different requirements requiring parametric approaches, parameterization methods describe the physical mechanism and characteristics of the rainfall-runoff process in the watershed as detailed as possible. They also develop a more complex mechanism. Simultaneously, exploration of the mechanism provides a systematic paradigm for describing the main principles needed to meet the demand for a practical development via a simple method.

\section{References}

Abbott M B, Bathhurst J C, Cunge J A et al., 1986a. An introduction to the European Hydrologic System-Systeme Hydrologique European, SHE: 1. History and philosophy of a physically based distributed modeling system. Journal of Hydrology, 87(1): 45-59.

Abbott M B, Bathhurst J C, Cunge J A et al., 1986b. An introduction to the European Hydrologic System-Systeme Hydrologique European, SHE: 2. Structure of a physically-based distributed modeling system. Journal of Hydrology, 87(1): 61-77.

Arnold J G, Williams J R, Srinivasan R et al., 1998. Large area hydrologic modeling and assessment (Part 1): Model development. Journal of the American Water Resources Association, 34(1): 73-89.

Bajracharya K, Barry D A, 1997. Accuracy criteria for linearised diffusion wave flood routing. Journal of Hydrology, 195(1): 200-217.

Bao W, 2006. Hydrologic Forecasting. Beijing: China Water \& Power Press. (in Chinese)

Bao W, Zhang J, 2008. Hydrologic Forecasting. Beijing: China Water \& Power Press. (in Chinese)

Beven K J, Kirkby M J, Schofield N et al., 1984. Testing a physically based flood-forecasting model (Topmodel) for three UK catchments. Journal of Hydrology, 69(1): 119-143.

Beven K, Lamb R, Quinn P et al., 1995. Topmodel. In: Computer Models of Watershed Hydrology. Colorado: Water Resources Publications, 627-668.

Cunge J A, 1969. On the subject of a flood propagation computation method (Muskingum Method). Journal of Hydraulic Research, 7(2): 205-230.

Entekhabi D, Asrar G R, Betts A K et al., 1999. An agenda for land surface hydrology research and a call for the second international hydrologic decade. Bulletin of the American Meteorological Society, 80(10): $2043-2058$.

Feldman A D, 1981. HEC models for water resources system simulation: Theory and experience. Advance in Hydroscience, 12: 297-423.

Govindaraju R S, Kavvas M L, Jones S E, 1990. Approximate analytical solutions for overland flows. Water Resources Research, 26(12): 2903-2912.

Green W H, Ampt G A, 1911. Studies on soil physics (Part 1): The flow of air and water through soils. The Journal of Agricultural Science, 4: 1-24.

Gupta V K, Waymire E, Wang C T, 1980. A representation of an instantaneous unit hydrograph from geomorphology. Water Resources Research, 16(5): 855-862.

Horton R E, 1935. Surface runoff phenomena. Horton Hydrology Laboratory.

Horton R E, 1940. An approach towards a physical interpretation of infiltration-capacity. Soil Science Society of 
America Journal, 5: 399-417.

Huber W C, Heaney J P et al., 2008. Storm Water Management Model User's Manual (Version 5.0). US: Environmental Protection Agency.

Jia Y, Ni G, Kawahara Y et al., 2001. Development of WEP model and its application to an urban watershed. Hydrologic Process, 15(11): 2175-2194.

Jia Y, Wang H, Zhou Z et al., 2006. Development of the WEP-L distributed hydrologic model and dynamic assessment of water resources in the Yellow River Basin. Journal of Hydrology, 331(3): 606-629.

Kuk-Hyun A, Venkatesh M, 2014. Quantifying the relative impact of climate and human activities on stream flow. Journal of Hydrology, 515: 257-266.

Lei X, Jiang Y, Wang H et al., 2010a. Distributed hydrologic model Easy DHM II: Application. Journal of Hydraulic Engineering, 41(8): 893-899. (in Chinese)

Lei X, Liao W, Jiang Y et al., 2010b. Distributed hydrologic model Easy DHM I: Theory. Journal of Hydraulic Engineering, 41(7): 786-794. (in Chinese)

Li J, Liu C, Wang Z et al., 2015. Two universal runoff yield models: SCS vs. LCM. Journal of Geographical Sciences, 25(3): 311-318.

Li Li, 2007. Study on flood routing of distributed hydrologic models [D]. Nanjing: Hohai University. (in Chinese)

Liang X, Lettenmaier D P, Wood E F, 1994. A simple hydrologically based model of land surface water and energy fluxes for general circulation models. Journal of Geophysical Research, 99(D7): 14415-14428.

Liang X, Wood E F, Lettenmaier D P, 1996. Surface soil moisture parameterization of the VIC-2L model: Evaluation and modification. Global and Planetary Change, 13(1): 195-206.

Liang W, Bai D, Wang F et al., 2015. Quantifying the impacts of climate change and ecological restoration on stream flow changes based on a Budyko hydrological model in China's Loess Plateau. Water Resources Research, 51(8): 6500-6519.

Linsley R K, Kohler M A, Paulhus J L et al., 1975. Hydrology for Engineers. New York: McGraw-Hill Book Company.

Liu C, Zheng H, Wang Z, 2006. Distribution Regional Hydrologic Cycle Simulation. Zhengzhou: Yellow River Conservancy Press. (in Chinese)

Liu C, Wang Z, Zheng H et al., 2008. Development and application of HIMS system and its custom model. Science in China Press E: Technology Science, 38(3): 350-360. (in Chinese)

Liu C, Wang Z, Yang S et al., 2014. Hydro-informatic modeling system: Aiming at water cycle in land surface material and energy exchange processes. Acta Geographica Sinica, 69(5): 579-587. (in Chinese)

Liu J, Qiang Z, Xi C et al., 2016. Quantitative evaluations of human- and climate-induced impacts on hydrological processes of China. Acta Geographica Sinica, 71(11): 1875-1885. (in Chinese)

Liu Z, Todini E, 2002. Towards a comprehensive physically-based rainfall-runoff model. Hydrology and Earth System Sciences Discussions, 6(5): 859-881.

Lu G, He H, 2006. View of global hydrologic cycle. Advances in Water Science, 17(3): 419-424. (in Chinese)

Lu G, Wu Z, He H, 2010. Hydrologic Cycle and Quantity Forecast. Beijing: Science Press. (in Chinese)

McCarthy G T, 1938. The unit hydrograph and flood routing. Conference of the North Atlantic Division of US Corps of Engineers.

Mishra S K, Singh V P, 2003. Soil Conservation Service Curve Number (SCS-CN) Methodology. Netherlands: Kluwer Academic Publishers.

Mo X, Liu S, 2004. Simulating the water balance of the Wuding River Basin in the Loess Plateau with a distribution eco-hydrologic model. Acta Geographica Sinica, 59(3): 341-348. (in Chinese)

Nash J E, 1957. The form of the instantaneous unit hydrograph. Hydrologic Science B, 45(3): 114-121.

Nash J E, 1960. A unit hydrograph study with particular reference to British catchments. Proceedings of the Institution of Civil Engineers B, 17(3): 249-282.

Neitsch S L, Arnold J G, Kiniry J R et al., 2011. Soil and Water Assessment Tool Theoretical Documentation (Version 2009). Texas Water Resources Institute.

Orlandini S, Perroti A, Sfondrini G et al., 1999. On the storm flow response of upland Alpine catchments. Hydrologic Processes, 13: 549-562.

Philip J R, 1954. An infiltration equation with physical significance. Soil Science, 77(2): 153-157.

Richards L A, 1931. Capillary conduction of liquids through porous mediums. Journal of Applied Physics, 1(5): 318-333. 
Rodriguez-Iturbe I, Valdes J B, 1979. The geomorphologic structure of hydrologic response. Water Resources Research, 15(6): 1409-1420.

Rui X, 1997. Some problems in research of watershed hydrology model. Advances in Water Science, 8(1): 94-98. (in Chinese)

Rui X, 2004. Principles of Hydrology. Beijing: China Water Power Press. (in Chinese)

Singh V P, 1988. Hydrologic Systems: Rainfall-Runoff Modeling. Englewood Cliffs: Prentice Hall.

Singh V P, 1994. Accuracy of kinematic wave and diffusion wave approximations for space-independent flows. Hydrologic Processes, 18(1): 45-62.

Singh V P, 1995. Computer Models of Watershed Hydrology. Colorado: Water Resources Publications.

Smith R E, Parlange J Y, 1978. A parameter-efficient hydrologic infiltration model. Water Resources Research, 14(3): 533-538.

Soil Conservation Service (SCS), 1993. National Engineering Hand-book. Section 4: Hydrology. USDA, Springfield, VA.

Skaggs R W, Khaleel R, 1982. Infiltration. In: Haan C T et al. (eds). Hydrologic Modeling of Small Watersheds. Am. Soc. Agric. Eng., St. Joseph, MI, 121-166.

Tang Q, Huang Z, Liu X et al., 2015. Impacts of human water use on the large-scale terrestrial water cycle. Advances in Earth Science, 30(10): 1091-1099. (in Chinese)

Ullah W, Dickinson W T, 1979a. Quantitative description of depression storage using a digital surface model: I. Determination of depression storage. Journal of Hydrology, 42(1/2): 63-75.

Ullah W, Dickinson W T, 1979b. Quantitative description of depression storage using a digital surface model: II. Characteristics of surface depressions. Journal of Hydrology, 42(1/2): 77-90.

USACE, 2000. HEC-HMS Hydrologic Modeling System Technical Reference Manual. Hydrologic Engineering Center, Davis, CA.

USACE, 2001. HEC-HMS Hydrologic Modeling System User's Manual. Hydrologic Engineering Center, Davis, CA.

Wang G, 2005. Theory and method of distributed time-variant gain model [D]. Beijing: IGSNRR. (in Chinese)

Wood E F, Sivapalan M, Beven K, 1988. Effects of spatial variability and scale with implications to hydrologic modeling. Journal of Hydrology, 102(1): 29-47.

Xia J, 2002a. A system approach to real time hydrologic forecasts in watersheds. Water International, 27(1): 87-97.

Xia J, 2002b. Theory and Method of Nonlinear Hydrologic System. Wuhan: Wuhan University Academic Library. (in Chinese)

Xia J, Duan Q, Luo Y et al., 2017. Climate change and water resources: Case study of Eastern Monsoon Region of China. Advances in Climate Change Research, 8: 63-67

Xia J, Wang G, Tan G et al., 2005a. Development of distributed time-variant gain model for nonlinear hydrologic systems. Science in China: Series D, 48(6): 713-723.

Xia J, Wang G, Ye A et al., 2005b. A distributed monthly water balance model for analyzing impacts of land cover change on flow regimes. Pedosphere, 15(6): 761-767.

$\mathrm{Xu} Z$, 2009. Hydrologic Model. Beijing: Science Press. (in Chinese)

Yuan F, Xie Z, Liu Q et al., 2004. An application of the VIC-3L land surface model and remote sensing data in simulating stream flow for the Hanjiang River basin. Canadian Journal of Remote Sensing, 30(5): 680-690.

Zhan D, Ye S, 2000. Engineering Hydrology. Beijing: China Water \&Power Press. (in Chinese)

Zhang Q, Liu J, Singh V P et al., 2016. Evaluation of impacts of climate change and human activities on stream flow in the Poyang Lake basin, China. Hydrological Processes, 30(14): 2562-2576.

Zhang S, Cordery L, Sharma A, 2002. Application of an improved linear storage routing model for the estimation of large floods. Journal of Hydrology, 258(1): 58-68.

Zhang W, Guo S, 2007. The Theory and Method of Rainfall-Runoff. Wuhan: Hubei Science and Technology Press. (in Chinese)

Zhao L, Xia J, Xu C et al., 2013. Evapotranspiration estimation methods in hydrological models. Journal of Geographical Sciences, 23(2): 359-369.

Zhao R, 1984. Regional Hydrologic Simulation: Xin'anjiang Model and Shanbei Model. Beijing: China Water \& Power Press. (in Chinese)

Zhao R, Zhuang Y, 1963. Regional pattern of rainfall-runoff relationship. Journal of East China Technical University of Water Resources Engineering, (Suppl.2): 53-68. (in Chinese) 